\title{
Metodologia Design Thinking no projeto de software para mobilidade urbana: relato de aplicação
}

\section{Applying design thinking in an urban mobility software project: an experience report}

\author{
Adailton Magalhães Lima ${ }^{1}$, Antonia Tamires Alves ${ }^{2}$, Anderson Jorge Serra da Costa ${ }^{1}$, Ernani de Oliveira Sales ${ }^{1}$ \\ ${ }^{1}$ Universidade Federal do Pará (UFPA), Belém, PA, Brasil \\ 2 Universidade Federal da Bahia (UFBA), Salvador, BA, Brasil
}

Autor para correspondência/Corresponding author: Adailton Magalhães Lima [ adailton@ufpa.br ]

Agradecimentos/Acknowledgments: Ao Coordenador e agentes da Secretaria Municipal de Transporte e Trânsito de Castanhal (SEMUTRAN), que colaboraram com insumos para a pesquisa realizada. À população entrevistada. A todos que auxiliaram o desenvolvimento deste projeto, direta ou indiretamente.

Recebido/Submitted: 30 Set. 2014

Aceito/Approved: 13 Dez. 2014

(2) Copyright (c) 2014 Lima, Alves, Costa, \& Sales. Todo o conteúdo da Revista está sob uma licença Creative Commons Atribuição-NãoComercial-Compartilhalgual 3.0 Não Adaptada. Ao serem publicados por esta Revista, os artigos são de livre uso em ambientes educacionais, de pesquisa e não comerciais, com atribuição de autoria obrigatória. Mais informações em http://www.atoz.ufpr.br/index.php/atoz/about/submissions\#copyrightNotice.

\section{Resumo}

Introdução: Apresenta um relato da condução de um estudo onde se aplicou a metodologia Design Thinking no contexto do projeto de uma solução de software ao contexto de mobilidade urbana.

Método: Dentre as técnicas sugeridas pela metodologia Design Thinking, este trabalho utilizou entrevistas, surveys, brainstorming e prototipação. O foco do estudo foram os transportes públicos e os processos intrínsecos a esse contexto.

Resultados: Tem-se um projeto de solução aderente aos problemas identificados nas pesquisas de campo, e também uma avaliação conduzida com os usuários alvo sobre o projeto de solução proposto.

Conclusão: A aplicação de Design Thinking pode ser eficiente no desenvolvimento de software, pois se tem nessa metodologia um direcionamento na elaboração de projetos centrada na construção de produtos voltados para atender as necessidades de seus usuários, ou seja, projeta-se a solução com base no quão usual o produto será para o usuário final.

Palavras-chave: Mobilidade Urbana. Gestão de transportes públicos. Design Thinking. Projeto de Software.

\begin{abstract}
Introduction: This paper presents a report about the conduction of a study where it was applied the Design Thinking methodology in the context of designing a software solution to urban mobility.

Method: Among the techniques suggested by Design Thinking methodology, this study applied interviews, surveys, brainstorming and prototyping. The focus of the study was the public transportation context and the intrinsic processes in this context.

Results: A software solution specification was developed based on the problems identified in field research, as well as an evaluation of the proposed solution conducted with the target users.

Conclusion: Applying Design Thinking can be efficient in software development because it provides a focus on developing solutions and products targeted to meet the needs of its users, in other words, designs the solution based on how the product will be useful for the end user.
\end{abstract}

Keywords: Urban Mobility. Public Transportation. Design Thinking. Software Project.

\section{INTRODUÇÃO}

Aliado à constante busca das organizações por qualidade está o conceito de inovação, onde se tem o desenvolvimento de novas soluções para os mais diversos tipos de negócios e problemas. Diferentemente de outras metodologias focadas no processo de Engenharia de Software (como RUP, XP etc.), a metodologia Design Thinking surge com a finalidade de auxiliar este processo de inovação e negócios, sem especificidade de área de aplicação, e que não tem, intencionalmente, direcionamento algum para o desenvolvimento de software (Silva, Silva Filho, Adler, Lucena, \& Russo, 2012).

Apesar de recentemente existirem vários casos de empresas startups desenvolvendo novos produtos de software e negócios, os relatos de experiência da aplicação da metodologia Design Thinking (DT) neste ramo ainda é incipiente. Como característica do Design Thinking tem-se a multidisciplinaridade, com técnicas e práticas que podem, com suas adequações, serem aplicadas a quase todo tipo de projeto, bem como é focada em atender as expectativas dos usuários do produto/serviço desenvolvido com base em sua estrutura (Silva, et al., 2012).

De acordo com Desconsi, 2012, o Design Thinking tem o poder de estimular, promover a inovação e transformar organizações e até mesmo sociedades através de seus métodos. Para isso, é necessário entender o papel do design e seu efeito através do pensamento multidisciplinar por meio da revisão da literatura, e identificar problemas com o conceito desenhado nas teorias de prática em sociologia, ciência e estudos de tecnologia e estudos de organização. Tais salvaguardas auxiliam no delineamento do campo do design e suas relações com os negócios, a gestão, a inovação e com isso tudo a cultura material do qual se inclui. O design parece ter 
deixado de ser uma competência de profissões enraizadas em economias industrializadas, para se tornar algo que todos podem praticar.

Para Brown (2010), a missão do Design Thinking é traduzir observações em insights, e estes em produtos e serviços para melhorar a vida das pessoas. Com isso, dado que esta metodologia atenta para criação de soluções que têm a preocupação de atender as necessidades dos usuários - além de suas fases de aplicação assemelharem-se a algumas etapas pertinentes ao ciclo de vida de um software (engenharia de requisitos, por exemplo) - torna-se relevante a análise desta metodologia no universo de desenvolvimento de software. Ressalta-se que o Design Thinking não tem especificidade de áreas de aplicação, ou seja, pode ser adaptado e aplicado a diversos tipos de projetos.

Pesquisadores destacam o envolvimento do usuário final em engenharia de software como um conceito importante para o desenvolvimento de sistemas úteis e utilizáveis. No entanto, o envolvimento do usuário final ainda é uma questão delicada. Novos paradigmas, como a computação ubíqua e orientada a serviços fortalecem a necessidade de envolvimento do usuário final mais ativo, a fim de fornecer sistemas personalizados que são adaptados às necessidades de usuários finais individuais (Seyff, Ollmann, \& Bortenschlager, 2011).

Neste contexto, o Design Thinking desponta como uma metodologia capaz de prover auxílio a essa necessidade exigida, dado que seu foco está no ser humano (usuário), além de se caracterizar como uma abordagem que vê na multidisciplinaridade, colaboração e percepção de pensamentos e processos de forma concreta, considerados caminhos que levam a soluções inovadoras para negócios (Silva, et al., 2012).

Neste trabalho foi escolhido o contexto de mobilidade urbana da cidade de Castanhal (PA), mais especificamente o âmbito dos transportes públicos. A motivação para esta escolha dá-se por consistir em um cenário real, bem como o serviço público de transporte é um dos principais utilizados pela sociedade. No estudo de campo realizado, através de abordagens aos funcionários da SEMUTRAN (Agentes e Coordenador) e aos usuários do serviço de transporte público do município, observou-se nos relatos que a população comumente evidencia situações de infrações e ilegalidades vivenciadas durante sua mobilidade ao utilizar os transportes públicos e, desta forma, sente-se no direito de impugnar tais ocorrências de maneira a denunciá-las. Visto isto, para mitigar tal problema, idealizou-se uma solução baseada em um aplicativo que viabilize a comunicação entre a população e a SEMUTRAN, de forma que os usuários de transporte público possam realizar denúncias e divulgar suas opiniões de insatisfação, no que se refere aos serviços prestados (ocorrência de infrações).

Para isto, pensou-se em aplicar DT como metodologia neste trabalho ao considerar que a mesma - com suas características referentes às técnicas intrínsecas às suas fases - possibilita que o objeto de estudo, no caso o contexto de mobilidade urbana da cidade, com foco nos transportes públicos, fosse analisado de maneira mais realista, possibilitando a imersão direta no cenário. Considera-se, ainda, a possibilidade, em médio prazo, de analisar os processos intrínsecos a esse tema, junto à instituição responsável pela gestão dos serviços públicos de transporte dispostos no município (SEMUTRAN), bem como com a população usuária e, através de observações de comportamentos dos stakeholders e do próprio processo motor do serviço público de transporte, identificar problemas reais e pertinentes. Além disto, dado que se trata de um trabalho que pretende atender diretamente uma significativa parcela da população, estima-se que DT possa prover o entendimento do que os envolvidos no universo do estudo "pensam" sobre o problema e "esperam" como solução. Isto consiste no pressuposto principal levantado neste estudo: a DT, aplicada como técnica auxiliadora ao processo de elicitação de requisitos, implica na criação de uma solução de software com maior proximidade ao que requisita as necessidades do usuário final.

O presente trabalho, portanto, apresenta o relato da experiência da aplicação de Design Thinking no projeto de uma solução de software voltada para a realização de denúncias de infrações evidenciadas durante a mobilidade de usuários de transportes públicos. Assim, apresentam-se na seção 2 os conceitos que acercam a metodologia Design Thinking; na seção 3 o relato do estudo de campo realizado; na seção 4 o protótipo da solução proposta ao problema identificado e sua validação e na seção 5 as considerações finais acerca do trabalho. 


\section{DESIGN THINKING}

O DT pode ser definido como uma nova aplicação do conceito de Design idealizada pela empresa norte-americana de consultoria IDEO $^{1}$, que apresenta uma metodologia visando proporcionar um caminho mais fácil, rápido e assertivo para a inovação de negócios. Conforme Lookwood (2009, p. 11), Design Thinking é:

Essencialmente um processo de inovação centrado no ser humano que enfatiza observação, colaboração, rápido aprendizado, visualização de ideias, construção rápida de protótipos de conceitos e análise de negócios dos concorrentes, para influenciar a inovação e a estratégia de negócio.

As fases do Design Thinking, como mostra a Figura 1, apesar de se apresentarem de forma linear, são aplicadas em ciclos de iteração não lineares e versáteis (Silva, et al., 2012). Isso porque suas fases podem, durante o processo de execução, serem ajustadas as necessidades do projeto, bem como ao contexto do problema. Tais realizações podem ocorrer de maneira independente, não sendo necessário esperar o término de uma fase para se iniciar outra. A seguir são apresentadas de maneira sucinta as principais fases que compreendem o ciclo de aplicação de Design Thinking:

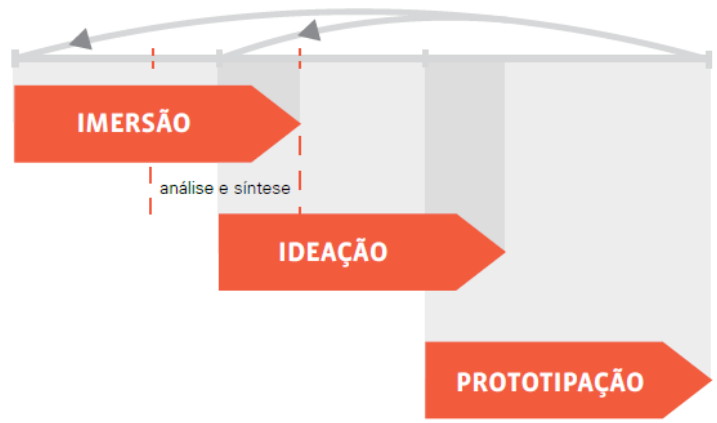

Figura 1. Esquema representativo das etapas do processo de Design Thinking. Fonte: Vianna, 2012. p 18.

\section{Fase de imersão}

A fase de Imersão é dividida em preliminar e em profundidade. Na imersão preliminar a equipe busca entender o universo do problema e o tema a ser estudado a partir de diversas perspectivas, obtendo diferentes pontos de vistas acerca deste. São realizadas pesquisas exploratórias em campo e pesquisas desk onde se procura por referências e fontes de informações em livros, na Internet, dentre outras. Bem como são identificados, nesta fase, os principais envolvidos na esfera do projeto, além de serem definidos o escopo, limites e restrições para o planejamento e execução do projeto.

A Imersão em profundidade inicia com uma pesquisa baseada em entrevistas, estruturadas e não estruturadas, realizadas com os principais interessados (stakeholders) a fim de explorar as visões acerca do contexto do problema. Objetiva-se, com isto, identificar o que implica direta e/ou indiretamente na vida das pessoas, leva-se em consideração aspectos positivos e negativos. Desta forma, reflexões são geradas e registradas e, a partir destas, são extraídos insights e conclusões preliminares sobre o tema trabalhado.

\section{Fase de Análise e Síntese}

Na fase de Análise e Síntese, como o próprio nome sugere, são realizadas a análise e a síntese das informações coletadas na fase de Imersão. O objetivo é identificar os principais problemas e pessoas (denominadas de "personas”) inerentes ao universo estudado. Além disto, determinam-se as primeiras ideias de solução a serem prototipadas. Em suma, se busca a compreensão, parcial ou total, do que é abordado no projeto.

\section{Fase de Ideação}

Na fase de Ideação acontece o brainstorming de ideias para gerar soluções inovadoras para o contexto estudado. Seções de brainstorming, por exemplo, são utilizadas nesta fase, dentre outras técnicas como workshops de co-criação e matrizes de posicionamento (Silva, et al., 2012). 


\section{Fase de Prototipação}

Nesta fase é quando de fato materializa-se a abstração feita na fase de Ideação, sobre as hipóteses de soluções apontadas como satisfatórias para sanar ou mitigar os problemas dos usuários. Assim, devem ser construídos protótipos de artefatos que representem os produtos e serviços criados para atender os problemas identificados.

\section{ESTUDO DE CAMPO}

O estudo realizado neste projeto objetivou identificar os fatores que implicam, direta e/ou indiretamente, na mobilidade urbana das pessoas que necessitam utilizar os transportes públicos para sua locomoção diária. Para isto, utilizou-se o contexto dos usuários de transportes públicos circulantes no município de Castanhal e localidades adjacentes (chamadas de agrovilas), que são esses: ônibus, táxi, mototáxis, vans, ônibus escolares e os ônibus que transportam os fornecedores de insumos agrícolas das agrovilas vizinhas ao município.

O estudo iniciou com uma busca abrangente de informações sobre mobilidade urbana no município como forma de permitir uma visão holística do contexto analisado. Tais problemas, relatados na seção 3.2, foram identificados através de questionamentos feitos com base nas informações coletadas através da observação e exploração dos fenômenos ocorridos no ambiente do problema estudado (relações, comportamentos, expectativas dos indivíduos, dentre outros).

Desta forma, pôde-se compreender o universo do problema, analisar o impacto deste no ser humano e, com isto, propor uma solução que se adéqua às necessidades dos sujeitos e se encaixe ao problema: buscou-se a percepção e compreensão através do pensamento abdutivo, o qual permite que 'design thinkers' explorem possibilidades olhando para o futuro, enquanto ainda analisam oportunidades olhando para o passado (Boer \& Bonini, 2010).

A seguir são apresentados os principais resultados do estudo de caso de acordo com as fases seguidas da metodologia Design Thinking até a fase de ideação. Os resultados da fase de prototipação são apresentados na seção 4, com o detalhamento do protótipo desenvolvido.

\section{Imersão}

Para obtenção de conhecimento prévio do contexto da pesquisa e delimitação do escopo do projeto realizouse, a priori, a imersão preliminar e em profundidade onde foram utilizadas as seguintes técnicas:

\section{Pesquisa Exploratória}

Nesta etapa realizou a observação do ambiente onde o problema está inserido, ou seja, saiu-se às ruas para observar os transportes públicos, sua circulação, a interação da população com o serviço público de transporte e a identificação das pessoas envolvidas neste contexto.

A partir desta fase pôde-se pensar nos temas centrais a serem abordados, e com isso, elaborar um roteiro para a pesquisa desk: buscar temas, problemas e soluções relacionadas ao caso estudado (transportes públicos e mobilidade urbana).

\section{Entrevistas}

Entrevistaram-se dez pessoas da população, usuários de transportes coletivos, e também cinco agentes de transporte e o próprio coordenador da secretaria de trânsito e transporte. O coordenador da secretaria de transportes pontuou as principais atividades realizadas pela secretaria, no que diz respeito ao planejamento, gestão controle e fiscalização dos transportes públicos da cidade, que são: planejamento dos itinerários dos ônibus; fiscalização dos transportes públicos (coletivos, táxi, mototáxis, vans, ônibus escolares e ônibus de transporte dos produtores agrícolas); e monitoramento dos itinerários dos coletivos. Quanto à população, foram levantados questionamentos sobre os problemas enfrentados durante sua mobilidade e os principais tipos de infrações que são evidenciadas no serviço público de transporte. 


\section{Pesquisa Desk}

A partir das informações coletadas nas primeiras entrevistas e nas observações da pesquisa exploratória, realizaram-se buscas na internet utilizando-se os seguintes termos: "Planejamento dos transportes públicos nas cidades", "Mobilidade Urbana", "Fiscalização de transportes públicos”, "Leis, normas e regulamentos sobre Mobilidade Urbana”. Dentre as normas identificadas no contexto de mobilidade urbana, destaca-se aqui a Lei $\mathrm{n}^{\circ} 12.587$ (de 3 de janeiro de 2012), intrínseca a nova Política Nacional de Mobilidade Urbana (PNMU).

Procurou-se também identificar sistemas web ou aplicativos que auxiliem a população em sua mobilidade urbana, a fim de encontrar características as quais se pudesse agregar a proposta deste trabalho. Como resultado encontrou-se as seguintes aplicações, por exemplo: Rota Urbana² ${ }^{2}$ SPTrans ${ }^{3}$ e o aplicativo Moovit ${ }^{4}$.

\section{Análise e síntese}

Analisando as informações coletadas nas entrevistas extraíram-se as principais atividades onde podem ocorrer problemas neste contexto, tais como:

a) Planejamento das rotas dos ônibus: Dada a necessidade de criação de uma nova rota (linha), os agentes de trânsito vão a campo e neste processo, ao percorrer as ruas, eles utilizam uma prancheta e caneta para rabiscar o desenho da rota viável durante percurso;

b) Fiscalização dos transportes: Neste processo, por exemplo, são observadas em campo, pelos agentes, as situações de ocorrência de infrações dos veículos no trânsito;

c) Monitoramento dos itinerários do ônibus: Os agentes encarregados das atividades de fiscalização e monitoramento ficam alocados em pontos estratégicos no centro da cidade e, através do documento de itinerários das linhas de ônibus, é feito o monitoramento onde é observado se os motoristas dos coletivos não estão descumprindo sua rota.

Assim, os principais perfis de usuários identificados ao contexto do problema, conhecidas como Personas, foram:

a) Gestor: Representante do poder público. Identificou-se esse perfil como um ponto chave na comunicação entre a população e a secretaria;

b) Agente: Representante dos fiscais de transportes públicos. Este perfil representa o canal direto da comunicação entre a população e a secretaria de transportes;

c) Usuário Estudante: Usuário do transporte público - escolar;

d) Usuário Agrícola: Usuário do transporte público - ônibus agrícola;

e) Usuário Intermediário: Usuário dos demais transportes públicos - vans, táxis, mototáxis e coletivos.

\section{Ideação}

Após definidas as personas e identificados os problemas mais pertinentes realizou-se então o processo de ideação, por meio de uma sessão de brainstorming, com a presença de um pesquisador experiente e um pesquisador auxiliar envolvidos diretamente na elaboração do projeto. Esta sessão foi baseada nas informações obtidas nas entrevistas feitas durante a fase de Imersão. Neste processo geraram-se as ideias para implementação do protótipo, onde o foco foi analisar as personas identificadas e direcionar as ideias para soluções que atendessem às suas necessidades.

\footnotetext{
${ }^{2}$ Ferramenta que auxilia o cidadão a se locomover pela cidade de forma a fornecer as rotas das linhas de ônibus da região. Baseado no conceito de Crowdsourcing, os usuários podem contribuir com o registro de rotas (Rota Urbana, 20130. Sistema disponível em: <www.rotaurbana. net.br>.

${ }^{3}$ Sistema Web da Prefeitura de São Paulo que auxilia a população com informações sobre os itinerários e rotas das linhas de ônibus circulantes na cidade. Sistema disponível em: <www.sptrans.com.br>.

${ }^{4}$ Aplicativo gratuito que auxilia os usuários de transporte público a traçarem rotas de circulação durante sua mobilidade por determinado percurso. Os usuários deste app, durante suas viagens, recebem e compartilham informações sobre todos os meios de transporte público em tempo real. Webpage do aplicativo disponível em: <www.moovitapp.com>.
} 
Durante aproximadamente duas horas foram expostas, em um quadro, as principais ideias organizadas dentro da regra: persona + problema enfrentado + solução. E, com base nisto, as primeiras ideias de funcionalidades para o aplicativo surgiram e foram definidas, conforme resumido no Quadro 1.

\begin{tabular}{|l|l|}
\hline \multicolumn{1}{|c|}{ Funcionalidade } & \multicolumn{1}{|c|}{ Descrição } \\
\hline $\begin{array}{l}\text { 1. Deve prover Feed de registros para os gestores de transporte } \\
\text { baseado em filtro por tipo de denúncia e região. }\end{array}$ & $\begin{array}{l}\text { Os gestores de transporte podem obter informações sobre as } \\
\text { ocorrências de infrações cometidas pelos provedores de serviços de } \\
\text { transporte público em suas cidades ou região. }\end{array}$ \\
\hline $\begin{array}{l}\text { 2. Deve permitir o georeferenciamento do local onde ocorreu a } \\
\text { infração ao se realizar uma denúncia. }\end{array}$ & $\begin{array}{l}\text { Utilização de mapa ou GPS para registro da localização do ponto } \\
\text { onde ocorreu a infração. }\end{array}$ \\
\hline $\begin{array}{l}\text { 3. Deve gerar relatório e estatísticas sobre as denúncias registradas } \\
\text { pela população }\end{array}$ & $\begin{array}{l}\text { A população pode visualizar dados estatísticos sobre a porcentagem } \\
\text { de infrações cometidas e denúncias realizadas. }\end{array}$ \\
\hline $\begin{array}{l}\text { 4. Deve permitir o anexo de evidências quando o reclamante reali- } \\
\text { zar uma denúncia. }\end{array}$ & $\begin{array}{l}\text { Ao realizar uma denúncia, o reclamante deve anexar evidências } \\
\text { (fotos, vídeos, imagens) que respaldem suas reclamaçães. }\end{array}$ \\
\hline $\begin{array}{l}\text { 5. Deve possibilitar ao usuário (reclamante) o acompanhamento de } \\
\text { sua denúncia. }\end{array}$ & $\begin{array}{l}\text { Ao fazer uma reclamação, esta fica pendente para validação. } \\
\text { Status: confirmada, pendente, falsa }\end{array}$ \\
\hline $\begin{array}{l}\text { 6. Deve ter integração com a rede social do usuário (caso o mesmo } \\
\text { possua). }\end{array}$ & $\begin{array}{l}\text { A pessoa realiza seu login na aplicação através do seu perfil em } \\
\text { rede social para compartilhar uma denúncia realizada. }\end{array}$ \\
\hline $\begin{array}{l}\text { 7. Deve permitir a população que realize uma denúncia em tempo } \\
\text { real ao fiscal de transporte. }\end{array}$ & $\begin{array}{l}\text { População pode avisar o fiscal através da realização de uma denún- } \\
\text { cia sobre uma infração cometida. }\end{array}$ \\
\hline $\begin{array}{l}\text { 8. Deve permitir que o gestor retorne uma resposta acerca da recla- } \\
\text { mação efetuada através de um comentário na denúncia realizada } \\
\text { ou email. }\end{array}$ & $\begin{array}{l}\text { Provê feedback ao reclamante sobre as medidas tomadas pelos } \\
\text { responsáveis por fazer a fiscalização. Pode ser: } \\
\text { O gestor informa a população através de uma resposta à } \\
\text { sua denúncia. } \\
\text { Reclamante responde ao gestor sobre o parecer tido do } \\
\text { mesmo a cerca de uma denúncia efetuada. }\end{array}$ \\
\hline
\end{tabular}

Quadro 1. Funcionalidades do mínimo produto viável para o Aplicativo Monitore.

Fonte: os pesquisadores com base na sessão de brainstorm, 2014.

\section{Solução proposta}

A partir das ideias geradas para a aplicação na fase de ideação, assim como os requisitos a serem atendidos descritos no Quadro1, foram pensadas duas hipóteses para o protótipo. Uma estava direcionada a projetar um sistema $w e b$. No entanto, após analisar o perfil das personas e o que era exigido pelas mesmas verificou-se que a proposta poderia ter mais aceitação se estivesse voltada para o conceito de computação móvel. Essa decisão se justifica pelas situações em que as pessoas, que evidenciam ocorrências de infrações, possivelmente usariam algum dispositivo móvel para realizar sua denúncia, além dos representantes da secretaria de transportes, receptores das reclamações, também estarem em constante locomoção nas ruas da cidade.

Desta forma, aderiu-se à hipótese de se projetar uma solução mobile. Com isso, começou-se a desenhar as primeiras ideias de telas para o App (aplicativo) com papel e caneta. $\mathrm{O}$ aplicativo projetado como solução para o problema abordado neste trabalho foi denominado "Monitore". Após isto, a ferramenta Fluidui ${ }^{5}$ foi utilizada para fazer o protótipo de telas, apresentado na próxima seção.

\section{Protótipo de telas}

Com base nas ideias geradas durante o brainstorming e na definição das funcionalidades que, possivelmente, assistiriam os usuários, projetaram-se então as telas do aplicativo, denominado "Monitore", conforme apresenta a Figura 2.

O Aplicativo Monitore foi projetado para atender todas as personas identificadas e tem seu foco na realização de denúncias sobre infrações cometidas nos transportes públicos da cidade, onde a população pode diretamente comunicar e evidenciar estas situações aos responsáveis por fiscalizar o serviço público de transporte, agentes e coordenador de transporte. Em sua tela principal, como mostra a Figura 2, o aplicativo disponibiliza quatro áreas principais para interação: “Registrar Denúncia”, “Quero Saber”, “Sou Gestor” e “Aqui, Agente!” descritas a seguir.

${ }^{5}$ Ferramenta Web utilizada para criação de protótipos de telas de projetos de software. Disponível em: <https://www.fluidui.com/>. 
Figura 2. Tela Inicial do Aplicativo Monitore. Fonte: autoria própria.

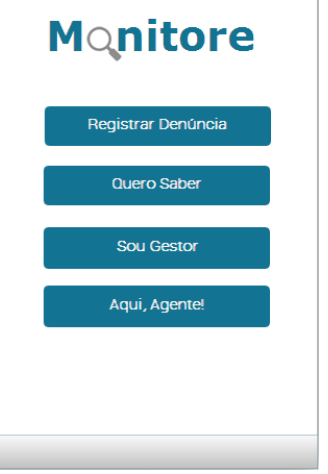

\section{Área "Registrar Denúncia"}

Esta seção foi direcionada para as personas representantes da população: o estudante, o agrícola e o intermediário. No entanto, as informações obtidas nesta seção favorecem também diretamente a persona gestor, representante do órgão gestor de transportes, pois nesta área pode-se efetivar uma denúncia. Para isso, é necessário que o usuário primeiramente realize o seu registro (Figura 3 - Tela 1) pois, ao se tratar deste tipo de circunstância - onde se expõe um infrator - é preferível inibir o anonimato do reclamante para se ter conhecimento de onde partiram as reclamações. Desta forma, os representantes da Secretaria podem saber a quem se dirigir, em caso de reclamações mais delicadas, como por exemplo: casos de infrações de desrespeito a deficientes físico, ou que portem qualquer outra deficiência.

Após registrar-se, como mostra a Figura 3, é preciso indicar o local onde ocorreu a infração (Tela 2), indicar o tipo de transporte envolvido no ocorrido (Tela 3), indicar o tipo de infração relacionada (Tela 4) e, por fim, descrever dados sobre o veículo (placa, por exemplo) e sobre a infração, além de anexar as evidências do fato, vídeos ou imagens (Tela 5).
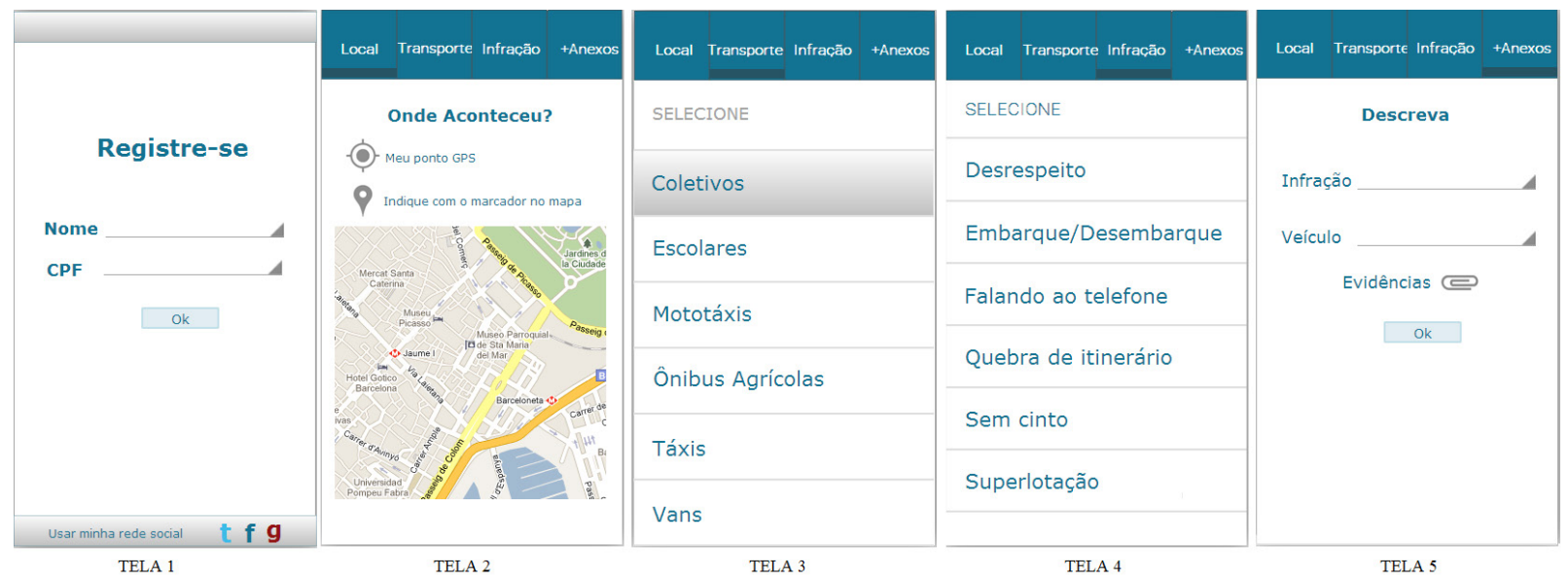

Figura 3. Passos para realizar uma denúncia. Fonte: autoria própria.

\section{Área "Quero Saber"}

Como se pode ver no esquema da Figura 4, nesta seção há três opções: Estatísticas, Feedback e Denúncias. Estas foram pensadas para que os usuários possam saber sobre estatísticas de infrações, buscando por tipo de veículo (Tela 1), ou por tipo de infração (Tela 2). Assim como aos que realizaram denúncias, são disponibilizadas duas áreas onde os mesmos podem verificar o status de confirmação de suas denúncias efetivadas, que podem ser consideradas como "confirmada", "falsa" ou "pendente", que não foi avaliada ainda (Tela 3), de igual forma podem falar diretamente com o representante da secretaria sobre a resposta obtida (Tela 4). 


\begin{tabular}{|c|c|c|c|c|}
\hline Lima, Alves, Costa, \& Sales & Metoc & $\begin{array}{l}\text { ologia design thinking no } \\
\text { tware para mobilidade ur }\end{array}$ & $\begin{array}{l}\text { ojeto de } \\
\text { ana }\end{array}$ & Z, 3(2), 128-138, jul./dez. 2 \\
\hline \begin{tabular}{l|l} 
Estatistica Feedback Denúncias \\
\end{tabular} & Estatistica Feedback Denúncias & Estatistica Feedback Denüncias & Estatistica Feedback Denúncias & Estatistica Feedback \\
\hline Buscar por Cidade/Estado & COLETIVO > INFRAÇÖES & MINHAS RECLAMAÇÖES & DENÚNCIA A & DENÚNCIAS CONFIRMADAS \\
\hline CASTANHAL & Desrespeito & Denúncia $A$ & Saiba mais! & Denúncia $A$ \\
\hline Coletivos & Desvio de rota & Denúncia $B$ & $\begin{array}{l}\text { Secretaria: } \\
\text { Olá, sua denúncia foi confirmada! A }\end{array}$ & fcompartilhar \\
\hline $30 \%$ & $2 \pi+\infty$ & & \begin{tabular}{|} 
secretaria tomará as medidas \\
cabiveis para punir o infrator!
\end{tabular} & Denúncia B \\
\hline Escolares & Falando ao telefone & Denúncia $C$ & Reclamante: & Denúncia C \\
\hline Mototáxis & Quebra de itinerário & Denúncia D & & \\
\hline Ônibus Agrícolas & Sem cinto & & Agradecemos sua colaboraçāo! & Denuncla D \\
\hline Táxis & Superlotação & & & \\
\hline Vans & Transbordo & Confirmada & Serviço de Ouvidoria & Compartilhe com seus amigos \\
\hline TELA 1 & TELA 2 & TELA 3 & TELA 4 & TELA 5 \\
\hline
\end{tabular}

Figura 4. Área de feedback ao usuário. Fonte: autoria própria.

\section{Área "Sou Gestor"}

O módulo “Sou Gestor”, representado na Figura 5, foi pensado estritamente para atender a persona gestor de transportes. Para a pessoa representada por este arquétipo é necessário prover informações e relatórios sobre os registros de denúncias efetivadas na sua cidade e/ou região. Para isso o gestor deve registrar-se (Tela 1), assim o mesmo pode obter informações sobre a porcentagem de registros de reclamações dos transportes públicos, buscando por tipo de denúncia ou região (Telas 2 e 3 , respectivamente) e, com isso, saber quais tipos de veículos recebem mais reclamações, bem como as infrações, além de poder solicitar recebimento de relatórios (Tela 4).

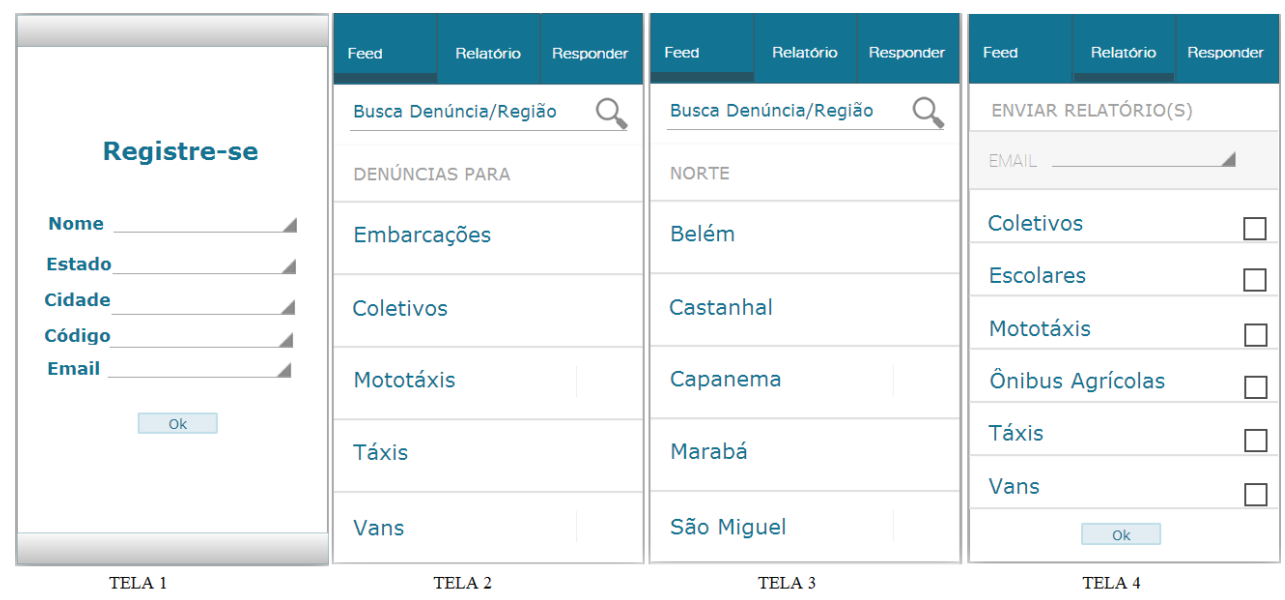

Figura 5. ÁÁrea de feedback ao Gestor. Fonte: autoria própria.

O Gestor pode também avaliar as denúncias reportadas, referentes à sua cidade, conforme Figura 6. Para isto, o mesmo busca denúncias efetivadas filtrando por tipo de transporte (Tela 1), ao selecionar uma denúncia é possível verificar a descrição da mesma (Tela 2), e ao selecionar a opção "evidências" o usuário poderá ver todas as evidências anexadas (Tela 3). Após avaliar a denúncia, o gestor atribui um Status para a mesma e provê uma resposta ao reclamante (Tela 4$)$.

\section{Área "Aqui, Agente!"}

Nesta seção o usuário pode, em tempo real, reportar uma reclamação sobre determinada infração evidenciada. A Figura 7 mostra as telas que o usuário visualiza quando seleciona esta área. São duas telas básicas, uma de registro (Tela 1) e outra com o chat, onde pode-se reportar uma reclamação diretamente ao Agente (Tela 2). Na mesma figura (Tela 3) é apresentada a notificação que aparece ao Agente, quando tem-se uma nova reclamação, a qual obterá resposta. 


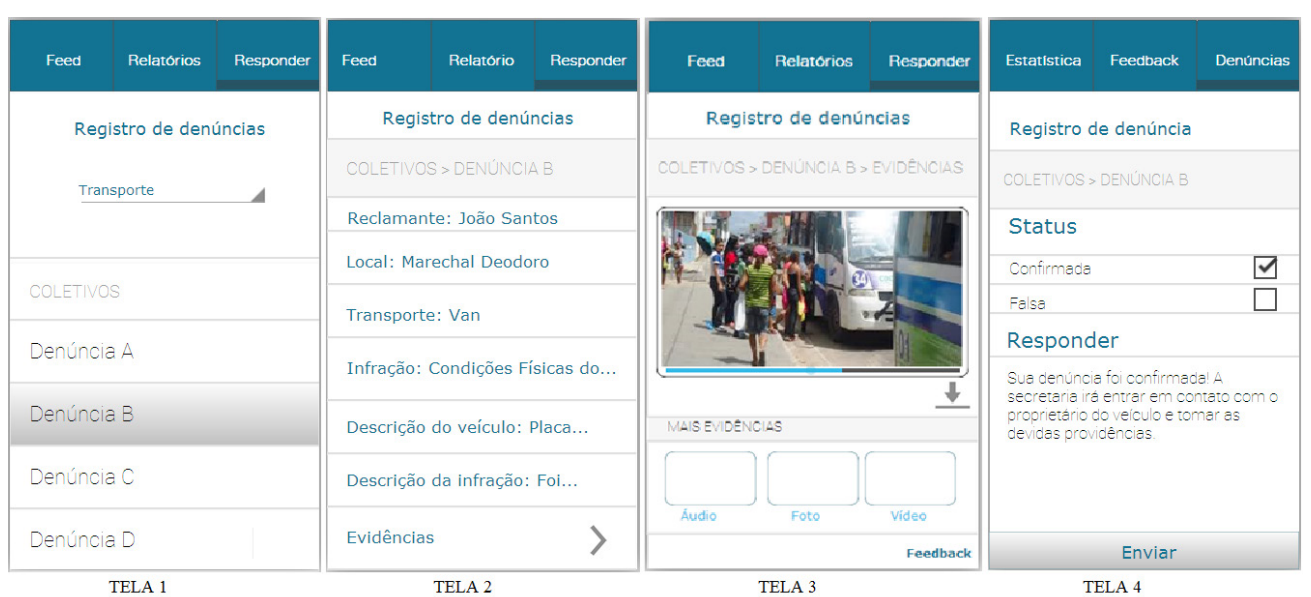

Figura 6. Análise de uma denúncia efetivada. Fonte: autoria própria.
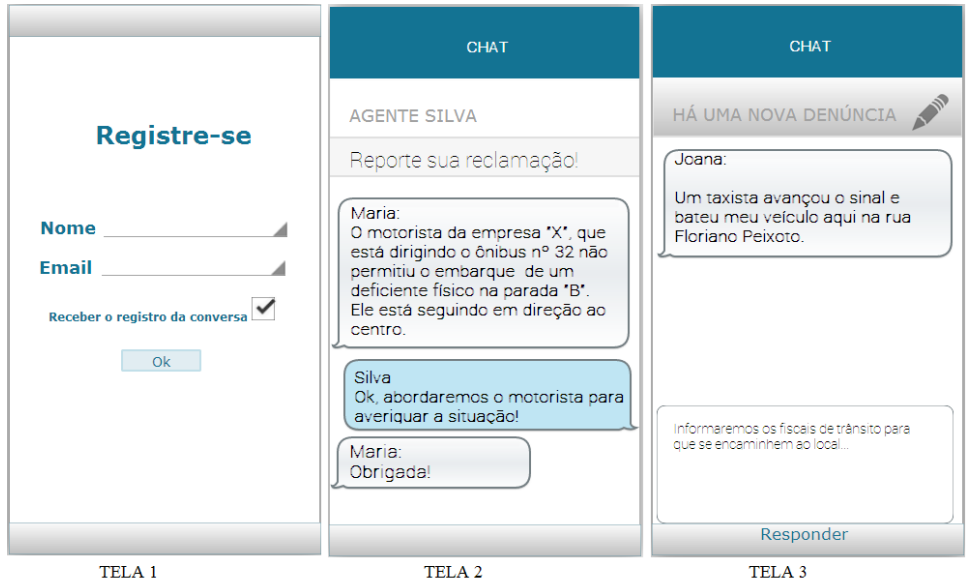

Figura 7. Chat com o agente de transporte.

Fonte: autoria própria.

\section{Avaliação}

Após a prototipação e para avaliar e validar a hipótese de solução proposta realizou-se um estudo campo onde se aplicaram questionários com a população para saber questões a respeito de sua mobilidade, bem como de sua avaliação sobre o protótipo, o seu esquema funcional foi apresentado na tela do celular.

Para tal, trinta pessoas - em uma faixa etária de 17 a 58 anos - foram escolhidas e abordadas aleatoriamente e solicitadas a responderem algumas questões, tais como: 1) Frequência em que utiliza os transportes públicos (coletivo, escolar, moto táxi, ônibus agrícola, táxi e van), se "nunca", "poucas vezes", "frequentemente" ou "sempre”; 2) Se já realizou algum tipo de denúncia; 3) Se utilizaria o aplicativo Monitore; 4) Se prefere realizar uma denúncia no momento em que a mesma acontece ou prefere deixar para depois (ao chegar em casa, por exemplo); 5) Indicar o grau de utilidade do aplicativo Monitore, no que atende às reclamações de problemas em transporte urbano - de 0 a 10; 6) Críticas, dicas, melhoria ou novas funcionalidade para o aplicativo.

Como resultado, observou-se que 100\% dos entrevistados utiliza os transportes públicos. Destes, 90\% são usuários frequentes de coletivos e10\% de escolares e, $65 \%$ relatou utilizar poucas vezes os seguintes meios de transporte: moto táxi, táxi e van (dessa margem a maioria utiliza mais coletivos) e $6 \%$ utiliza sempre o ônibus de transporte agrícola. Verificou-se também que a maioria (97\%) nunca realizou uma reclamação sobre infrações evidenciadas durante sua mobilidade ao utilizar o serviço público de transporte, ou "por medo de repressão", ou "por não encontrar no momento do fato um agente de transporte no local". Dos respondentes, 83\% utilizariam o aplicativo para realizar uma denúncia e, destes, 3\% que não o utilizariam corresponde aos usuários na faixa etária mais alta; possivelmente não familiarizados com o uso desse tipo de tecnologia. Todos os respondentes relataram que gostariam de realizar a denúncia no momento em que a mesma ocorreu, e a maioria concordou que "é melhor para não esquecer detalhes da infração". Quanto ao grau de utilidade do 
app Monitore, 60\% atribuíram grau "8”, 23\% acharam a proposta muito boa e atribuíram “9” e 16\% atribuíram grau " 10 ".

\section{CONSIDERAÇÕES FINAIS}

Neste trabalho foi apresentado o relato da experiência sobre a aplicação de uma abordagem multidisciplinar dirigida para o desenvolvimento de projetos inovadores - Design Thinking - na criação de um projeto de software relacionado ao contexto de mobilidade urbana, conforme estudo de caso abordado.

Com o estudo levantado notou-se que a aplicação de Design Thinking pode ser eficiente no desenvolvimento de software, pois se tem nessa metodologia um direcionamento na elaboração de projetos centrada na construção de produtos voltados para atender as necessidades de seus usuários, ou seja, projeta-se a solução com base no quão usual o produto será para o usuário final. Assim como suas fases e técnicas não se distanciam dos processos comumente adotados no ciclo de desenvolvimento de software, uma vez que suas fases podem ser facilmente mescladas, como por exemplo: A imersão, ideação e prototipação auxiliam na elicitação de requisitos e, até mesmo, no projeto do produto final.

Pensa-se, também, que a utilização das técnicas de Design Thinking no processo de elicitação de requisitos pode agregar maior grau de proximidade à realidade das necessidades dos usuários, isso aponta uma forma de evitar problemas na má compreensão e interpretação, quanto às requisições do cliente. Segundo Kujala (2003), o envolvimento do usuário geralmente tem efeitos positivos no sucesso do sistema e satisfação do usuário, e existe evidência de que opiniões dadas pelos usuários, como uma busca por primeiras informações, são algo efetivo da elicitação de requisitos.

Para Vertterli et al. (2013), o Design Thinking é consistente com as práticas iniciais de elicitação, inerentes a engenharia de requisitos, prototipagem rápida, relacionamento com o cliente e apresenta-se com um método ágil. Esta metodologia auxilia, no que tange a organização de um projeto de software, tanto a documentação dos requisitos, quanto a gestão de equipe e, como supracitado, seu foco é direcionado para o desenvolvimento ágil. No entanto, esta metodologia tem suas limitações, no que se refere a este contexto de aplicação, visto que no desenvolvimento de software sabe-se que existem documentações técnicas específicas que auxiliam a condução do projeto, desde sua fase inicial até a construção do produto final. Visto isso, existe a necessidade de agregar artefatos e documentos de Engenharia de Software como forma de complemento às fases de condução do Design Thinking.

Como forma de tornar mais eficiente algumas fases de desenvolvimento de software, nota-se que a mescla de Design Thinking com a metodologia Lean Startup (Ries, 2012) pode agregar efeitos positivos, em especial ao que se refere à engenharia de requisitos e validação de produtos de software, uma vez que esta última contribui para avaliar a aceitação do produto final com base na análise de seus usuários finais e, com isso, verificar se as hipóteses de solução são aceitáveis e se realmente satisfazem às necessidades dos usuários. 


\section{REFERÊNCIAS}

Boer, G., \& Bonini, L. (2010). Design thinking: Uma nova abordagem para inovação. [Biblioteca TerraForum]. Retirado de http://biblioteca. terraforum.com.br/BibliotecaArtigo/artigo-designthinking.pdf

Brown, T. (2010). Design thinking: Uma metodologia poderosa para decretar o fim das velhas ideias. Rio de Janeiro: Elsevier.

Desconsi, J. (2012). Design thinking como um conjunto de procedimentos para a geração da inovação: Um estudo de caso do projeta do G3. (Dissertação de Mestrado). Centro Universitário Ritter dos Reis. Porto Alegre.

Kujala, S. (2003). User involvement: A review of the benefits and challenges. Behaviour \& Information Technology, 22(1), 1-16. Retirado de http://mcom.cit.ie/staff/Computing/prothwell/hci/ papers/UserInvolvement.pdf

\section{Como citar este artigo (ABNT):}

LIMA, A. M.; ALVES, A. T.; COSTA, A. J. da.; SALES, E. O. Metodologia design thinking no projeto de software para mobilidade urbana: relato de aplicação. AtoZ: novas práticas em informação e conhecimento, Curitiba, v. 3, n. 2, p. 128-138, jul./dez. 2014. Disponível em: <http:// www.atoz.ufpr.br>. Acesso em:
Loockwood, T. (2009). Design thinking: Integrating innovation, customer experience, and brand value. Nova York: Allworth.

Ries, E. (2012). A startup enxuta. São Paulo: Lua de Papel.

Rota Urbana. (2013). Rota Urbana. Retirado de http://www. rotaurbana.net.br/

Seyff, N., Ollmann G., \& Bortenschlager, M. (2011). iRequire: gathering end-user requirements for new apps. 19th IEEE Internacional Requirements Engineering Conference, 347-348. Retirado de http://ieeexplore.ieee.org.ez10.periodicos.capes. gov.br/stamp/stamp.jsp?tp=\&arnumber $=6051669$

Silva, M. J. V., Silva Filho, Y. V., Adler, I. K., Lucena, B. F., \& Russo, B. (2012). Design thinking: Inovação em negócios. Rio de Janeiro: MJV.
How to cite this article (APA):

Lima, A. M., Alves, A. T., Costa, A. J., \& Sales, E. (2014). Metodologia design thinking no projeto de software para mobilidade urbana: Relato de aplicação. AtoZ: novas práticas em informação e conhecimento, 3(2), 128-138. Retrieved from http://www.atoz.ufpr.br 